
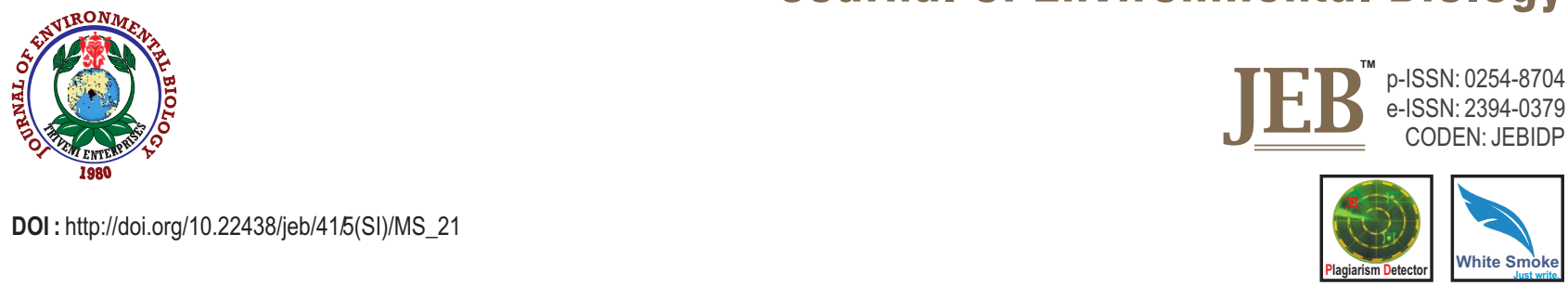

\title{
Foraging dependency of Barbour's seahorse Hippocampus barbouri (Jordan and Richardson 1908) juveniles on photoperiod and light intensity
}

\author{
V.W.C. Er ${ }^{1}$, A. Christianus ${ }^{1,2 *}$, Z.M Harah', C.M. Chong ${ }^{2}$ and M.S. Ismail ${ }^{3}$ \\ ${ }^{1}$ Institute of Bioscience, Universiti Putra Malaysia, 43400 Serdang, Selangor, Malaysia \\ ${ }^{2}$ Department of Aquaculture, Faculty of Agriculture, Universiti Putra Malaysia, 43400 Serdang, Selangor, Malaysia \\ ${ }^{3}$ Tunku Abdul Rahman Aquarium, Fisheries Research Institute, 11960 Batu Maung, Penang, Malaysia \\ *Corresponding Author Email : annie@upm.edu.my
}

\section{Abstract}

Aim: To determine the effect of photoperiod and light intensity on the growth and survival of $H$. barbourijuveniles.

Methodology: In the first experiment, three photoperiod ratios were tested 8L:16D (Light: Dark), 12L:12D and 16L:8D. Light-emitting diode (LED) of approximate intensity of $2100 \mathrm{~lx}$ was used. In the second experiment, three light intensities were used: 700, 1400 and $2100 \mathrm{~lx}$. Both experiments were conducted for 4 weeks.

Results: At the end of 4 week culture period, the highest survival of $H$. barbouri juveniles was $80 \%$ under photoperiod of 12L:12D, followed by $66.67 \%$ under $8 \mathrm{~L}: 16 \mathrm{D}$, and the lowest $56.67 \%$ under $16 \mathrm{~L}: 8 \mathrm{D}$. The results showed that photoperiod of 12L:12D produced the best height $37.71 \mathrm{~mm}$ and weight $0.165 \mathrm{~g}$ of $H$. barbouri juveniles. As for the experiment on light intensity, the highest survival of $H$. barbouri juveniles was $86.67 \%$ under $1400 \mathrm{~lx}$, followed by $80 \%$ under $2100 \mathrm{~lx}$, and the lowest $60 \%$ under $700 \mathrm{~lx}$. At the end of the experiment, the light intensity of 1400 and $2100 \mathrm{~lx}$ showed the maximum growth with respect to height 35.31 and $37.71 \mathrm{~mm}$ and weight 0.133 and $0.165 \mathrm{~g}$.

Interpretation: The overall results suggested that $H$. barbouri juveniles could be cultured under photoperiod of 12L:12D and light intensity of 1400 to $2100 \mathrm{~lx}$ for conducive growth and survival.

Key words: Hippocampus barbouri, Light intensity, Photoperiod

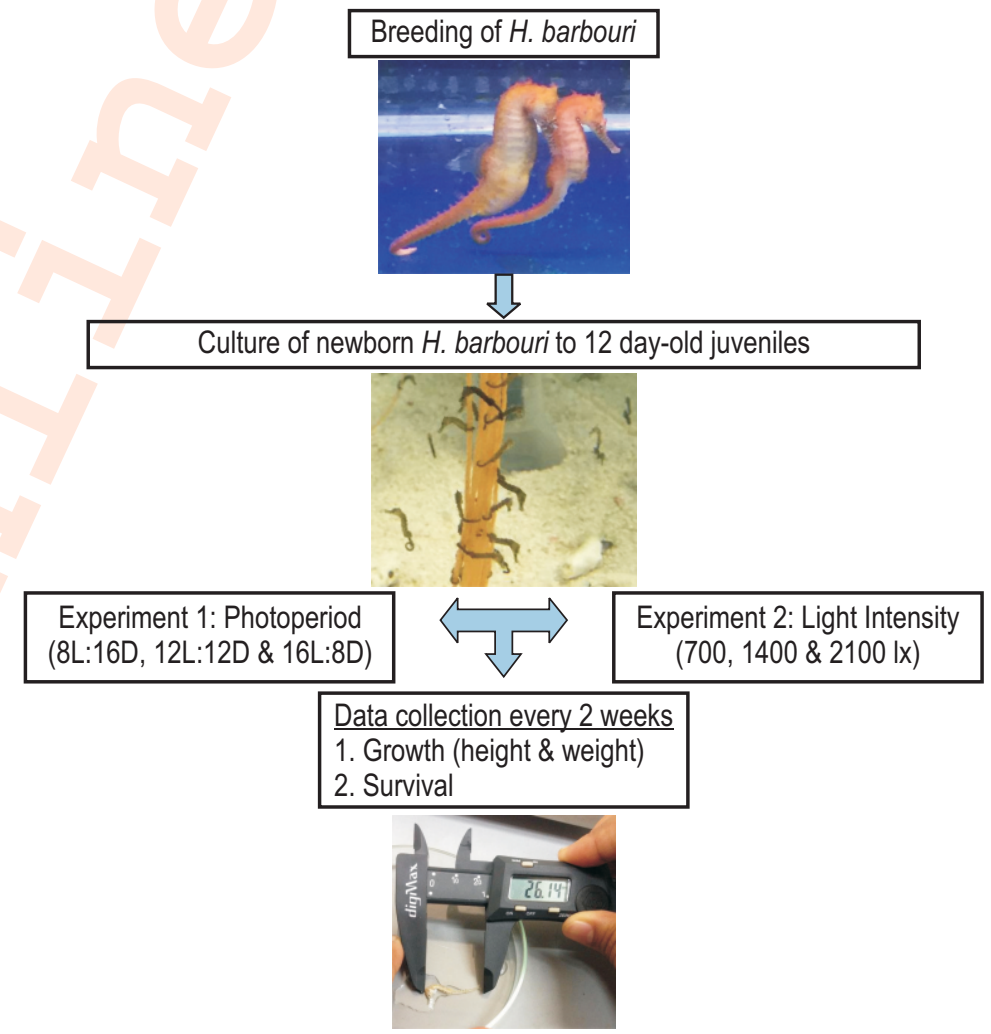

How to cite : Er, V.W.C., A. Christianus, Z.M. Harah, C.M. Chong and M.S. Ismail: Foraging dependency of Barbour's seahorse Hippocampus barbouri (Jordan and Richardson 1908) juveniles on photoperiod and light intensity. J. Environ. Biol., 41, 1281-1288 (2020). 


\section{Introduction}

Seahorse species are distributed in coastal tropical, subtropical and temperate marine regions all over the world (Olivotto et al., 2011). According to Foster and Vincent (2004), seahorses usually inhabit regions with seagrass beds. All seahorse species are listed in the Convention on International Trade in Endangered Species of Wild Fauna and Flora (CITES) appendix II as vulnerable, mainly due to degradation of habitat (Short et al., 2011), overexploitation (Foster and Vincent, 2004) and by catch (Scales, 2010; Vincent et al., 2011). No doubt research on the biology of seahorses have increased in the last decade, nonetheless detailed information on most species are still lacking due to their species-specific needs.

Photoperiod influences the physiological activities of fish. It can be manipulated to increase the growth of fish, thereby reducing the culture time and enabling early marketing of fish. Prolonged photoperiod at early stages of fish has proved to enhance the growth rate of several marine fish such as Pagrus auratus (Fielder et al., 2002), Sparus aurata (Gines et al., 2004), Melanogrammus aeglefinus (Tripple and Neil, 2003) and Pagrus major (Biswas et al., 2005). Culture activities of seahorse are usually carried out under natural photoperiod. Ratio of 12 hour light and 12 darkness (12L:12D) has been applied on species like H. whitei (Wong and Benzie, 2003) and H. abdominalis (Woods, 2005).

Another factor often overlooked is light intensity. It can affect predation effort in fish (Batty, 1987) as some fish species become more active at higher light intensities, for instance, Clupea harengus larvae and H. zosterea (Batty, 1987; Strawn, 1958; Giwojna and Giwojna, 1999). Studies related to light intensity on seahorses were restricted to species like $H$. abdominalis, $H$. trimaculatus, $H$. whitei and $H$. erectus (Woods, 2000a; Wong and Benzie, 2003; Sheng et al., 2006; Lin et al., 2009; Lin etal., 2010).

As a visual predator, conditions like photoperiod and light intensity are important to ensure seahorses can prey effectively. Hence, the objective of this study was to determine the effect of photoperiod and light intensity on the growth and survival of $H$. barbourijuveniles.

\section{Materials and Methods}

Experiments using different photoperiods and light intensities were conducted concurrently for 4 weeks at the Aquarium Tunku Abdul Rahman, Fisheries Research Institute, Batu Maung, Penang, Malaysia. Seahorse juveniles used for each experiment was obtained from a single brood. The dimension of the experimental tanks used was $17 \times 24 \times 32 \mathrm{~cm}$ with approximate volume of 10 I seawater. The tanks covered with black canvas (except for those exposed to natural light intensity) to avoid external light penetration during the experimental period. Experimental tanks were equipped with Dophin $\mathrm{H} 100$ power filters and $18 \mathrm{~cm}$ nylon strings tied with weights to act as holdfast for the seahorse juveniles. Previous studies have shown that a nursing duration of 12 days resulted in improved growth and survival of $H$. barbouri juveniles. Hence, twelve-day-old $H$. barbouri juveniles were used for the experiments. All treatments were triplicated with ten seahorses in each tank, as newborns of H. barbouriper brood was limited.

Height and weight of the seahorse juveniles were taken at the initiation and then at 2 week interval until the end of the study period. Height was measured following the protocol by Lourie et al. (1999), which is from the top of the coronet to the tip of the straightened tail using a digital vernier caliper (Mitutoyo, Japan). Seahorses were weighed using microbalance (Mettler Toledo, PB 303 I) after being pat-dried with a paper towel. Survival was recorded throughout the experimental period. Seahorse juveniles were fed daily with newly hatched Artemia nauplii (Bio-Marine, USA) to observed satiation at 09:30 and 15:30 hrs. Faeces were siphoned before each feeding.

YSI Professional Plus Multi-parameter was used to measure temperature, salinity, $\mathrm{pH}$ and dissolved oxygen. Whereas ammonia, nitrite and nitrate were estimated with API salt-water test kit. Data analysis was conducted using SPSS version 21.0. Experimental data (growth and survival) were analyzed using One-way of Analysis of Variance (ANOVA) where Tukey test was used as a post-hoc test to group the treatments of significant differences. Survival data were transformed using Arcsine prior to ANOVA. The results were presented as mean \pm standard deviation.

Photoperiod : Photoperiods tested were 8L:16D, 12L:12D and 16L:8D. Light-emitting diode (LED) used was with light intensity of approximately $2100 \mathrm{Ix}$. All lights were placed $30 \mathrm{~cm}$ above the water level. These photoperiods were controlled with timers.

Light intensity : Three light intensities used were natural light, fluorescent light and LED with corresponding light intensities of approximately 700,1400 and $2100 \mathrm{~lx}$, respectively. Fluorescent light and LED were placed $30 \mathrm{~cm}$ above the water level. Light intensities were monitored daily using a light meter (CENTER 337). Photoperiod for this study was fixed at 12L:12D.

\section{Results and Discussion}

Studies on the impact of photoperiod on seahorses meagre. As seahorses are visual predators, they depend highly on the availability of light for foraging, therefore, determination of suitable photoperiod is useful for the optimization of culture practices (Tucker, 1998) since it is known to affect the growth and survival of fish larvae (Partridge et al., 2011; Stuart and Drawbridge, 2012; Valles and Estevez, 2013). Natural 
photoperiod has been in selected few seahorse species like $H$. kuda, H. barbouri, H. fucus, H. erectus (Wilson and Vincent, 1998; Correa et al., 1989) to mimic the natural environment. Photoperiod of 12L:12D is commonly used in the culture practices for species like $H$. whitei, $H$. subelongatus, and $H$. abdominalis (Wong and Benzie, 2003; Payne and Rippingale, 2000; Woods, 2003; Wilson et al., 2006). It is believed that such photoperiod is suitable for the growth of seahorses. Due to its species-specific effect, it is crucial to determine the optimum photoperiod for each species.

Continuous light availability of 24I : OD for culturing $H$. reidi has resulted in better culture as compared to the natural photoperiod. This shows that with longer light duration, seahorse juveniles are able to forage longer, resulting in better growth. Similar findings have been reported on the ornamental and commercial species (Barlow et al., 1995; Job et al., 1997; Avella et al., 2007). In this study, 24L: OD photoperiod was omitted due to mass mortality during a preliminary study. $H$. abdominalis juveniles showed least growth under continuous light of 24L: OD as compared to $16 \mathrm{~L}: 8 \mathrm{D}$ in a study carried out by Martinez-

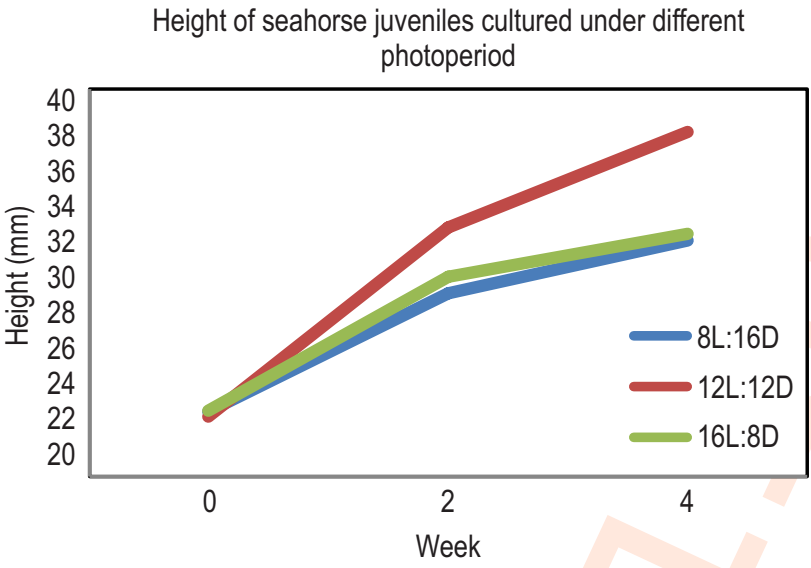

Fig. 1 : Height of seahorse juveniles cultured under different photoperiod.

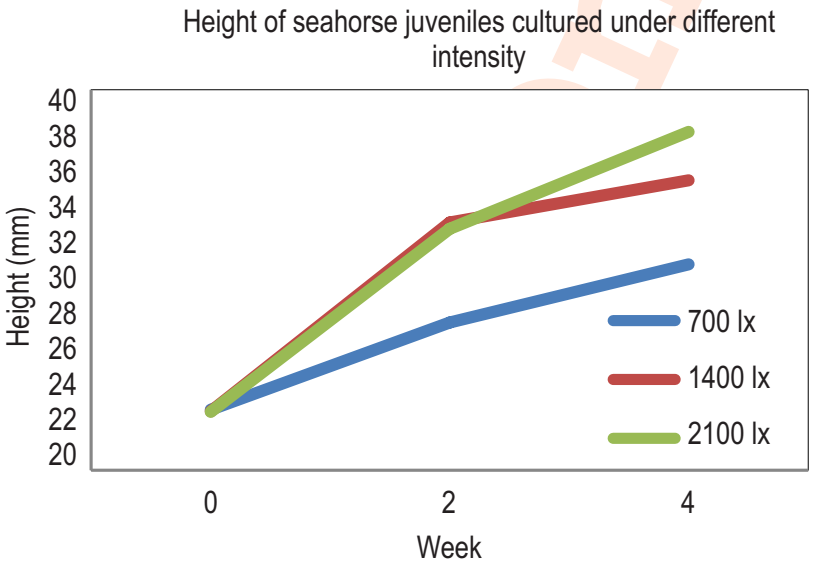

Fig. 3 : Height of seahorse juveniles cultured under different light intensity.
Cardenas and Purser (2012). Similarly, marine fish larvae such as snapper (Fielder et al., 2002) and Gilthead sea bream (Gines et al., 2004) showed low mass gain when cultured under continuous light of 24 | :0D. Almazan-Rueda et al. (2005) stated that continuous light (24 I :0D) in marine fish rearing can introduce stress in the form of negative social interaction, resulting in lower growth and survival. According to Woods (2000b), excessive tail grasping may stress the seahorses.

At the initiation of the experiment, the height and weight of $H$. barbouri juveniles ranged between 23.10 and $23.40 \mathrm{~mm}$ and within 0.047 to $0.049 \mathrm{~g}$, respectively. Initial height and weight were not significantly different ( $p>0.05)$ among treatments (Table 1). After 2 weeks, the height of $H$. barbouri juveniles under photoperiod ratio of $12 \mathrm{~L}: 12 \mathrm{D}$ was significantly higher $(p<0.05)$ than those under 8L:16D and 16L:8D (Fig. 1). Similarly, at the end of the experimental period, the height of $H$. barbouri juveniles under 12L:12D photoperiod was highest $(37.71 \mathrm{~mm}, \mathrm{p}<0.05)$ as compared to the other two treatments. As for weight, after 2 weeks, $H$. barbouri juveniles under 12L:12D showed significantly higher $(p<0.05)$ weights than juveniles under 8L:16D, however

Weight of seahorse juveniles cultured under different photoperiod

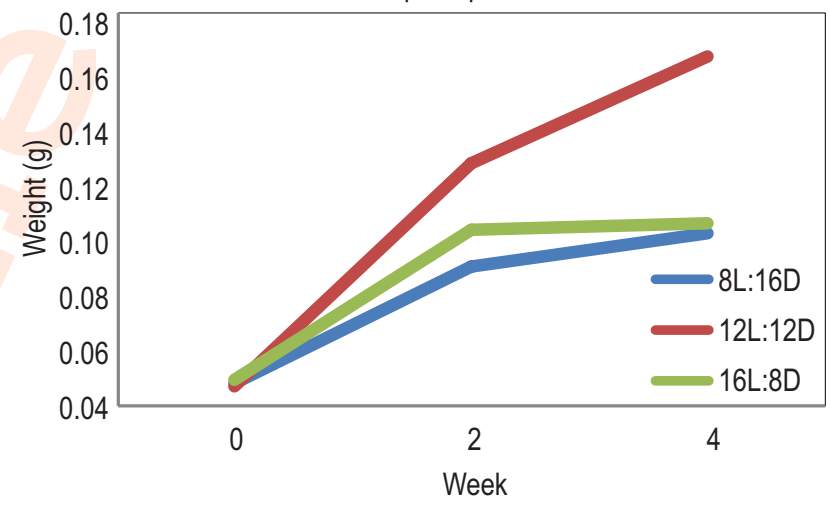

Fig. 2 : Weight of seahorse juveniles cultured under different photoperiod.

Weight of seahorse juveniles cultured under different intensity

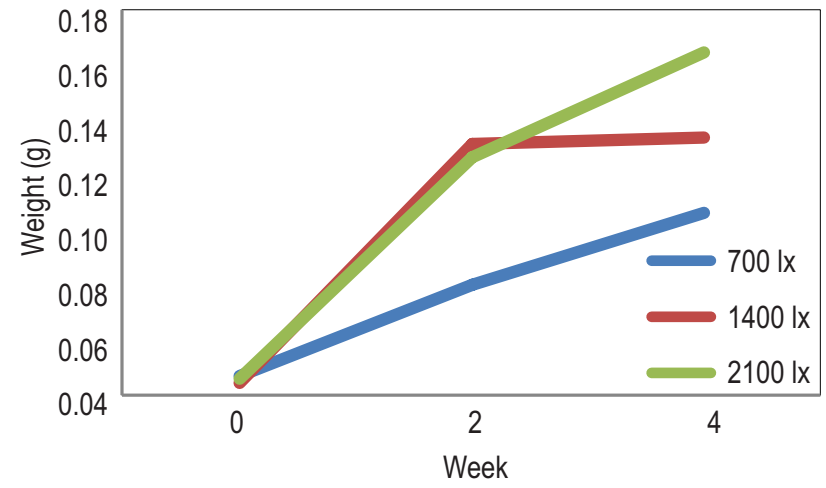

Fig. 4 : Weight of seahorse juveniles cultured under different light intensity. 
with no significant $(p>0.05)$ difference when compared to juveniles under 16L:8D (Fig. 2). At the end of the experimental period, the weight of $H$. barbouri juveniles under 12L:12D was significantly highest $(0.165 \pm 0.053 \mathrm{~g}, \mathrm{p}<0.05)$ as compared to those under $8 \mathrm{I}: 16 \mathrm{D}$ and $16 \mathrm{~L}: 8 \mathrm{D}$, with respective weights of 0.102 $\mathrm{g}$ and $0.105 \mathrm{~g}$, respectively.

In the present study, photoperiod of $16 \mathrm{~L}: 8 \mathrm{D}$ did not give better results. Seahorse juveniles tend to spend more time 'wrestling' against each other due to long light hours, resulting in higher energy expenditure and lower growth performance. In this case, extended photoperiod may not be suitable for $\mathrm{H}$. barbouri juveniles, therefore, photoperiod likely has a species-specific effect on $H$. barbouri. Another possibility is that at extended photoperiod of $16 \mathrm{~L}: 8 \mathrm{D}$, the juveniles will spend longer time foraging causing lower food intake, thus higher energy expenditure. When food intake is low, it will not be able to compensate for the energy lost after the long hours of foraging.

In the present study, $H$. barbouri juveniles survived best under photoperiod of 12L:12D. Without visibility time spent on foraging, swimming and 'wrestling' is minimized. This shows that energy saved by seahorses during the dark hours may be used for growth. This rationale is in agreement with other studies (Fielder et al., 2002; Stuart and Drawbridge, 2012; Blanco et al., 2011, 2013; Cunha et al., 2007). Survival during 12L:12D is highest indicating that this is the best photoperiod for better survival of $H$. barbouri juveniles. Similarly, European sea bass (Villamizar et al., 2009) and Senegal sole larvae (Blanco-Vives et al., 2010) showed better growth under photoperiod of $12 \mathrm{~L}: 12 \mathrm{D}$
Photoperiod of 8L:16D showed slow growth of seahorse juveniles in the current study. Similarly, a study by Hora et al. (2017) found that growth and survival of $H$. reidi juveniles were lower at photoperiod of 6L:18D. Seahorses may not have sufficient time to feed during the short duration of visibility, therefore less feeding may result in slower growth. Survival of $H$. barbouri at shortest (8L:16D) and longest (16L:8D) duration of visibility results in lower survival as compared to 12L:12D. In the case of $H$. guttulatus juveniles, culture under natural and extended photoperiod did not affect the growth and survival (Blanco et al., 2014)

Survival of $H$. barbouri juveniles (Table 2) throughout the 4-week experimental period under photoperiod of 8L:16D, 12L:12D and 16L:8D decreased from 100 to $93.33 \%, 96.67 \%$ and $86.67 \%$, respectively. At the end of week 4 , the highest survival of $H$. barbouri juveniles were $80 \%$ under photoperiod of 12L: 12D, followed by $66.67 \%$ under $8 \mathrm{~L}: 16 \mathrm{D}$, and the lowest $56.67 \%$ under 16L:8D. The reported low survival of $H$. abdominalis juveniles under 16L:8D (Martinez-Cardenas and Purser, 2012) is supported by the findings of the present study with lowest survival of $H$. barbouri juveniles under photoperiod of 16L:8D. According to Blanco et al. (2014), this occurs due to the imbalance between ingested and mobilized energy.

Some fishes use vision to detect and capture their prey (Blaxter, 1980). Visibility increases with the presence of light. As light increases, it may affect prey capture (Batty, 1987), consequently affecting growth and survival. Woods (2000a) stated that seahorse juveniles are photo positive from newborn onwards. At

Table 1 : Growth (height and weight) of $H$. barbourijuveniles cultured for 4 weeks under different photoperiods

\begin{tabular}{|c|c|c|c|c|c|c|}
\hline \multirow[t]{3}{*}{$\overline{\text { Week }}$} & \multicolumn{3}{|c|}{ Height (mm) } & \multicolumn{3}{|c|}{ Weight (g) } \\
\hline & \multicolumn{6}{|c|}{ Photoperiod } \\
\hline & 8L:16D & 12L:12D & 16L:8D & 8L:16D & 12L:12D & 16L:8D \\
\hline 0 & $23.33 \pm 1.19^{\mathrm{a}}$ & $23.10 \pm 1.19^{\mathrm{a}}$ & $23.40 \pm 1.13^{\mathrm{a}}$ & $0.048 \pm 0.009^{a}$ & $0.047 \pm 0.006^{a}$ & $0.049 \pm 0.007^{\mathrm{a}}$ \\
\hline 2 & $29.39 \pm 2.41^{b}$ & $32.83 \pm 3.93^{\mathrm{a}}$ & $30.27 \pm 3.02^{b}$ & $0.090 \pm 0.027^{\mathrm{b}}$ & $0.127 \pm 0.052^{\mathrm{a}}$ & $0.103 \pm 0.032^{\mathrm{ab}}$ \\
\hline 4 & $32.20 \pm 1.77^{b}$ & $37.71 \pm 3.64^{\mathrm{a}}$ & $32.47 \pm 2.53^{\mathrm{b}}$ & $0.102 \pm 0.028^{b}$ & $0.165 \pm 0.053^{\mathrm{a}}$ & $0.105 \pm 0.027^{b}$ \\
\hline
\end{tabular}

Mean \pm S.D. with the same superscripts within the same row are not significantly different $(p>0.05)$; L, Light; $D$, Darkness

Table 2 : Survival of $H$. barbourijuveniles under different photoperiods throughout the experimental period

\begin{tabular}{|c|c|c|c|}
\hline \multirow[t]{3}{*}{ Week } & \multirow[b]{2}{*}{ 8L:16D } & \multicolumn{2}{|l|}{ Photoperiod } \\
\hline & & 12L:12D & 16L:8D \\
\hline & & \multicolumn{2}{|l|}{ Survival (\%) } \\
\hline 0 & $100 \pm 0.00$ & $100 \pm 0.00$ & $100 \pm 0.00$ \\
\hline 2 & $93.33 \pm 5.77$ & $96.67 \pm 5.77$ & $86.67 \pm 5.77$ \\
\hline 4 & $66.67 \pm 15.28$ & $80.00 \pm 10.00$ & $56.67 \pm 15.28$ \\
\hline
\end{tabular}

L, Light; D, Darkness 
Table 3: Growth of Hippocampus barbourijuveniles cultured for 4 weeks under different light intensities

\begin{tabular}{|c|c|c|c|c|c|c|}
\hline \multirow[t]{3}{*}{ Week } & \multicolumn{3}{|c|}{ Height (mm) } & \multicolumn{3}{|c|}{ Weight (g) } \\
\hline & \multicolumn{6}{|c|}{ Light intensity (Ix) } \\
\hline & 700 & 1400 & 2100 & 700 & 1400 & 2100 \\
\hline 0 & $23.17 \pm 1.15^{\mathrm{a}}$ & $23.10 \pm 1.19^{\mathrm{a}}$ & $23.07 \pm 1.17^{\mathrm{a}}$ & $0.047 \pm 0.008^{a}$ & $0.044 \pm 0.007^{a}$ & $0.046 \pm 0.006^{\mathrm{a}}$ \\
\hline 2 & $27.83 \pm 3.31^{\mathrm{b}}$ & $33.07 \pm 2.70^{\mathrm{a}}$ & $32.76 \pm 4.07^{\mathrm{a}}$ & $0.080 \pm 0.035^{b}$ & $0.131 \pm 0.034^{\mathrm{a}}$ & $0.127 \pm 0.052^{\mathrm{a}}$ \\
\hline 4 & $30.78 \pm 7.75^{\mathrm{b}}$ & $35.31 \pm 2.40^{\mathrm{a}}$ & $37.71 \pm 3.64^{\mathrm{a}}$ & $0.106 \pm 0.034^{b}$ & $0.133 \pm 0.030^{b}$ & $0.165 \pm 0.053^{\mathrm{a}}$ \\
\hline
\end{tabular}

Mean \pm S.D. with the same superscripts within the same row are not significantly different $(p>0.05)$

Table 4 : Survival of $H$. barbourijuveniles under different light intensity throughout the experimental period

\begin{tabular}{|c|c|c|c|}
\hline \multirow[t]{3}{*}{ Week } & \multicolumn{3}{|c|}{ Light intensity (Ix) } \\
\hline & 700 & 1400 & 2100 \\
\hline & & Survival (\%) & \\
\hline 0 & $100 \pm 0.00$ & $100 \pm 0.00$ & $100 \pm 0.00$ \\
\hline 2 & $96.67 \pm 5.77$ & $100 \pm 0.00$ & $96.67 \pm 5.77$ \\
\hline 4 & $60.00 \pm 17.32$ & $86.67 \pm 15.28$ & $80.00 \pm 10.00$ \\
\hline
\end{tabular}

the beginning of this experiment, the heights and weights of $H$. barbouri juveniles were between 23.07 to $23.17 \mathrm{~mm}$ and 0.044 to $0.047 \mathrm{~g}$, respectively. The initial height and weight were not significantly different ( $p>0.05$ ) among treatments (Table 3 ). After 2 weeks of culture, the height of $H$. barbouri juveniles under light intensity of 1400 and 2100 Ix were significantly higher $(p<0.05)$ as compared to juveniles under light intensity of $700 \mathrm{~lx}$ (Fig. 3). Similarly, at the end of the experimental period, the height of $H$. barbouri juveniles under 1400 and 2100 Ix intensities were higher $(p<0.05)$ ( 35.31 and $37.71 \mathrm{~mm}$ ), respectively, as compared to $H$. barbouri juveniles under $700 \mathrm{~lx}(30.78 \mathrm{~mm})$. Between the natural light $(700 \mathrm{~lx})$, fluorescent light $(1400 \mathrm{~lx})$ and LED (2100 lx), seahorse juveniles showed better growth at intensities between 1400 and $2100 \mathrm{~lx}$ as compared to $700 \mathrm{~lx}$. Lin et al. (2009) recommended that $H$. erectus requires high light intensity of 1000 Ix for culture.

As for weight, after first 2 weeks of culture, $H$. barbouri juveniles under light intensity of 1400 and 2100 Ix showed significantly greater $(p<0.05)$ weight than those juveniles under light intensity of $700 \mathrm{~lx}$ (Fig. 4). However, at the end of week 4, $\mathrm{H}$. barbouri juveniles under light intensity of $2100 \mathrm{~lx}$ showed the maximum weight $(p<0.05)$ of $0.165 \mathrm{~g}$ as compared to those juveniles cultured under light intensity of 700 and $1400 \mathrm{Ix} \mathrm{(0.106}$ and $0.133 \mathrm{~g}$ ), respectively. The final weights of seahorse juveniles cultured under $2100 \mathrm{~lx}$ was higher than those of 1400 and $700 \mathrm{~lx}$. However, the survival of seahorse juveniles cultured under 1400 Ix was higher when compared to those of 2100 and 700 Ix. This finding contradicts Lin et al. (2010) who reported that $H$. erectus juveniles showed the best survival at $500 \mathrm{Ix}$.
Survival of $H$. barbouri juveniles (Table 4) under light intensity of $700 \mathrm{~lx}, 1400 \mathrm{~lx}$ and $2100 \mathrm{~lx}$ dropped from $100 \%$ to $96.67 \%, 86.67 \%$ and $80 \%$, respectively. At the end of 4-week culture period, the highest survival of juveniles was $86.67 \%$ under $1400 \mathrm{~lx}$, followed by $80 \%$ under $2100 \mathrm{~lx}$, and the lowest 60 $\%$ under $700 \mathrm{~lx}$. Studies show that the growth of $H$. whitei was not affected by different natural light ranges (Wong and Benzie, 2003). However, the growth of $H$. erectus under 500 lx was relatively low for the first few weeks but increased thereafter (Lin et al., 2009). In contrast with the present study, $H$. barbouri juveniles grew better with the increase in light intensity. This may be because the light intensities tested are within the threshold required by seahorse juveniles.

In the present study, the feeding effort of $H$. barbouri juveniles reared under 1400 and 2100 lx was higher compared to $700 \mathrm{~lx}$. This is consistent with the findings of Woods (2000a) and Lin et al. (2010). Feeding effort of $H$. trimaculatus juveniles peaked at light intensity of $1500 \mathrm{~lx}$ and required lower light intensities during feeding as they grew (Sheng et al., 2006). These differences may be result of changes in eye sensitivity with development. The optimal light intensity may be different for seahorses at different life stages (Lin et al., 2009).

Low water quality affects the health of seahorse and to certain extent may even result in mortality (Len et al., 2020). Table 5 shows the water parameters monitored during the 4-weeks experiment on photoperiod. Temperature and salinity fluctuated slightly for all treatments, with readings ranging from 27.0 to 29.0 ${ }^{\circ} \mathrm{C}$ and 30.0 ppt to $32.6 \mathrm{ppt}$, respectively. Water $\mathrm{pH}$ for all 
Table 5 : Water quality parameters measured throughout the study period for the experiment on photoperiod

\begin{tabular}{llllll}
\hline Water parameter & Photoperiod (L:D) & \multicolumn{3}{c}{ Week } \\
\cline { 3 - 6 } & & $\mathbf{1}$ & $\mathbf{2}$ & $\mathbf{3}$ & $\mathbf{4}$ \\
\hline Temperature $\left({ }^{\circ} \mathrm{C}\right)$ & $8: 16$ & 27.0 & 27.5 & 28.5 & 29.0 \\
& $12: 12$ & 27.0 & 27.5 & 28.5 & 29.0 \\
& $16: 8$ & 27.0 & 27.5 & 28.5 & 29.0 \\
Salinity (ppt) & $8: 16$ & 30.0 & 30.3 & 32.6 & 31.6 \\
& $12: 12$ & 30.0 & 30.0 & 32.0 & 31.6 \\
& $16: 8$ & 30.0 & 30.0 & 31.0 & 31.3 \\
pH & $8: 16$ & 7.6 & 7.6 & 7.6 & 7.6 \\
& $12: 12$ & 7.6 & 7.6 & 7.6 & 7.6 \\
DO (mg/L) & $16: 8$ & 7.6 & 7.6 & 7.6 & 6.4 \\
& $8: 16$ & 6.8 & 6.6 & 6.4 & 6.2 \\
Ammonia (ppm) & $12: 12$ & 6.8 & 6.8 & 6.4 & 6.4 \\
& $16: 8$ & 6.8 & 0.6 & 6.6 & 0.0 \\
Nitrite (ppm) & $8: 16$ & 0.0 & 0.0 & 0.0 & 0.0 \\
& $12: 12$ & 0.0 & 0.0 & 0.0 & 0.0 \\
Nitrate (ppm) & $16: 8$ & 0.0 & 0.0 & 0.0 & 0.0 \\
& $12: 16$ & 0.0 & 0.0 & 0.0 & 0.0 \\
& $16: 8$ & 0.0 & 0.0 & 0.0 & 0.0 \\
& $12: 16$ & 0.0 & 0.0 & 0.0 & 0.0 \\
& $16: 8$ & 0.0 & 0.0 & 0.0 & 0.0 \\
\hline
\end{tabular}

L, Light; D, Darkness

Table 6 : Water quality parameters measured throughout the study period for experiment on light intensity

\begin{tabular}{|c|c|c|c|c|c|}
\hline \multirow[t]{2}{*}{ Water parameter } & \multirow[t]{2}{*}{ Light intensity (Ix) } & \multicolumn{4}{|c|}{ Week } \\
\hline & & 1 & 2 & 3 & 4 \\
\hline \multirow[t]{3}{*}{ Temperature $\left({ }^{\circ} \mathrm{C}\right)$} & 700 & 26.5 & 27.0 & 27.5 & 28.0 \\
\hline & 1400 & 27.0 & 27.5 & 28.5 & 30.0 \\
\hline & 2100 & 27.0 & 27.5 & 28.5 & 29.0 \\
\hline \multirow[t]{3}{*}{ Salinity (ppt) } & 700 & 30.0 & 30.0 & 31.3 & 31.3 \\
\hline & 1400 & 30.0 & 30.0 & 30.6 & 31.0 \\
\hline & 2100 & 30.0 & 30.0 & 32.0 & 31.6 \\
\hline \multirow[t]{3}{*}{$\mathrm{pH}$} & 700 & 7.6 & 7.6 & 7.6 & 7.6 \\
\hline & 1400 & 7.6 & 7.6 & 7.6 & 7.6 \\
\hline & 2100 & 7.6 & 7.6 & 7.6 & 7.6 \\
\hline \multirow[t]{3}{*}{$\mathrm{DO}(\mathrm{mg} / \mathrm{L})$} & 700 & 6.4 & 6.6 & 6.4 & 6.2 \\
\hline & 1400 & 6.4 & 6.4 & 6.4 & 6.2 \\
\hline & 2100 & 6.4 & 6.2 & 6.2 & 6.4 \\
\hline \multirow[t]{3}{*}{ Ammonia (ppm) } & 700 & 0.0 & 0.0 & 0.0 & 0.0 \\
\hline & 1400 & 0.0 & 0.0 & 0.0 & 0.0 \\
\hline & 2100 & 0.0 & 0.0 & 0.0 & 0.0 \\
\hline \multirow[t]{3}{*}{ Nitrite (ppm) } & 700 & 0.0 & 0.0 & 0.0 & 0.0 \\
\hline & 1400 & 0.0 & 0.0 & 0.0 & 0.0 \\
\hline & 2100 & 0.0 & 0.0 & 0.0 & 0.0 \\
\hline \multirow{3}{*}{ Nitrate (ppm) } & 700 & 0.0 & 0.0 & 0.0 & 0.0 \\
\hline & 1400 & 0.0 & 0.0 & 0.0 & 0.0 \\
\hline & 2100 & 0.0 & 0.0 & 0.0 & 0.0 \\
\hline
\end{tabular}


treatments were stable at 7.6 throughout the study period. As for $\mathrm{DO}$, all treatments had their DO levels above $6 \mathrm{mg} \mathrm{l}^{-1}$, while ammonia, nitrite and nitrate in all treatments were at $0 \mathrm{ppm}$ throughout the experimental period. Water parameters measured during the 4-week experiment on light intensity is shown in Table 6. Water temperature fluctuations for tanks with light intensities of 700,1400 and $2100 \mathrm{~lx}$ were 26.5 to $28.0^{\circ} \mathrm{C}, 27.0$ to $30.0^{\circ} \mathrm{C}$ and 27.0 to $29.0^{\circ} \mathrm{C}$, respectively. The salinity levels fluctuated slightly for all treatments, with readings ranging from 30.0 to $32.0 \mathrm{ppt}$. Water $\mathrm{pH}$ for all treatments were stable at 7.6 throughout the study period, while DO readings for all treatments were above 6 $\mathrm{mg} \mathrm{l}^{-1}$. Ammonia, nitrite and nitrate in all treatments were $0 \mathrm{ppm}$ throughout the experimental period.

In the present study, temperature fluctuated from 27.0 to $29.0^{\circ} \mathrm{C}$ during the study period. This notably high fluctuation is due to the rainy season causing drastic changes in ambient temperature therefore affecting the water temperature as well. As for salinity, slight fluctuation between 30.0 and $32.0 \mathrm{ppt}$ for all the treatments is considered safe for the growth and survival of $H$. barbouri as the salinity of their natural habitat in Borneo is 34.0 ppt. Thus, mortalities due to salinity fluctuation or incompatibility is unlikely. However, further studies should be conducted to confirm this. In the present study, water pH of 7.6 was within the permissible limit for the culture of aquatic organisms as described by Boyd (1979), while DO above $6 \mathrm{mg} \mathrm{l}^{-1}$ is above the sufficient level $\left(5 \mathrm{mg} \mathrm{l}^{-1}\right)$ for most aquatic species, including $H$. barbouri. According to Boyd (1979) low DO may affect growth and to certain extend leads to mortality. In the present study, the installed filtration system effectively eliminates ammonia, nitrite and nitrate from the culture water. Hence, this rules out the possibility of the above water parameters as causal factor for the mortality in seahorse.

Based on the findings of this study, it shows that the foraging ability of $H$. barbourijuveniles is very much dependent on the presence of light. Photoperiod set at $12 \mathrm{~L}: 12 \mathrm{D}$ with light intensity of 1400 to $2100 \mathrm{~lx}$ is recommended for favourable growth and survival of these juveniles. Higher light intensities can be tested in future studies to determine the optimum light intensity for seahorse juveniles.

\section{Acknowledgment}

Authors would like to thank the Ministry of Higher Education Malaysia for funding this study through Fundamental Research Grant Scheme (FRGS/1/2013/SG03/UPM/02/2, Vot No: 5524306).

\section{References}

Almazan-Rueda, P., A.T. Helmond, J.A. Verreth and J.W. Schrama: Photoperiod affects growth, behavior and stress variables in Clarias gariepinus. J. Fish Biol., 67, 1029-1039 (2005).

Avella, M., I. Olivotto, G. Gioacchini, F. Maradonna and O. Carnevali: The role of fatty acids enrichments in the larviculture of false percula clownfish Amphiprion ocellaris. Aquaculture, 273, 87-95 (2007).

Barlow, C., M. Pearce, L. Rodgers and P. Clayton: Effects of photoperiod on growth, survival and feeding periodicity of larval and juvenile barramundi Lates calcarifer (Bloch). Aquaculture, 138, 159-168 (1995).

Batty, R.S.: Effect of light intensity on activity and food-searching of larval herring, Clupea harengus: A laboratory study. Mar. Biol., 94, 323327 (1987).

Biswas, A.K., M. Seoka, Y. Inoue, K. Takii and H. Kumai: Photoperiod influences the growth, food intake, feed efficiency and digestibility of red sea bream (Pagrus major). Aquaculture, 250, 666-673 (2005).

Blanco, A., P. Quintas and M. Planas: Enhancement in the rearing of the seahorse Hippocampus guttulatus by feeding on copepods. $5^{\text {th }}$ International Zoo and Aquarium Symposium The husbandry, Management and Conservation of Syngnathids, Chicago, Illinois (USA) (2011).

Blanco, A., M. Planas and F.J. Moyano: Digestive enzyme activities of juvenile seahorses Hippocampus guttulatus fed on different live prey. Aquaculture Europe (2013).

Blanco, A., A. Chamorro and M. Planas: Implications of physical key factors in the early rearing of the long-snouted seahorse Hippocampus guttulatus. Aquaculture, 433, 214-222 (2014).

Blanco-Vives, B., N. Villamizar, J. Ramos, M. Bayarri, O. Chereguini and F. Sánchez-Vázquez: Effect of daily thermo- and photo-cycles of different light spectrum on the development of Senegal sole (Solea senegalensis) larvae. Aquaculture, 306, 137-145 (2010).

Blaxter, J.H.S.: Vision and feeding of fishes. In: Fish behavior and its use in the capture and culture of fishes, ICLARM Conference Proceedings (Eds.: J.E. Bardach, J.J. Magnuson, R.C. May and J.M. Reinhart). ICLARM, Manila, Philippines, pp. 32-56 (1980).

Boyd, C.F.: Water quality in warm water fish pond. Auburn University, Alabama (1979).

Correa, M., K.S. Chung and R. Manrique: Experimental culture of the seahorse, Hippocampus erectus. Boletin del Instituto Oceanografico de Venezuela. Cumana, 28, 191-196 (1989).

Cunha, I., L.E. Conceição and M. Planas: Energy allocation and metabolic scope in early turbot, Scophthalmus maximus, larvae. Mar. Biol., 151, 1397-1405 (2007).

Fielder, D., W.J. Bardsley, G.L. Allan and P.M. Pankhurst: Effect of photoperiod on growth and survival of snapper Pagrus auratus larvae. Aquaculture, 211, 135-150 (2002).

Foster, S.J. and A.C. Vincent: Life history and ecology of seahorses: Implications for conservation and management. J. Fish Biol., 65, 161 (2004).

Gines, R., J.M. Afonso, A. Arguello, M.J. Zamorano and J.L. Lopez: The effects of long-day photoperiod on growth, body composition and skin color in immature gilthead sea bream (Sparus aurata). Aquaculture Research, 35, 1207-1212 (2004).

Giwojna, P. and B. Giwojna: Seahorse breeding secrets: Part I. Ten common mistakes and how to avoid them. Freshwater and Marine Aquarium, 1, 8-27 (1999).

Hora, M.D.S.C.D., J.C. Joyeux, H.C. Guabiroba and M.Y. Tsuzuki: Effect of photoperiod and tank color on growth and survival of pelagicphase seahorse Hippocampus reidi. Aquac. Res., 48, 4300-4307 (2017).

Job, S., M. Arvedlund and M. Marnane: Captive breeding of coral reef fishes. AustraliaAquaculture, 11, 56-59 (1997). 
Len, Y.W., A. Christianus, S. Worachanant, Z. Mutaharah and C.M. Chong: Estimation of live food consumption for Hippocampus bardouti and Hippocampus kuda. J. Surv. Fisher. Sci., 7, 43-54 (2020).

Lin, Q., J. Lin and L. Huang: Effects of light intensity, stocking density and temperature on the air-bubble disease, survivorship and growth of early juvenile seahorse Hippocampus erectus Perry, 1810. Aquac.Res., 42, 91-98 (2010).

Lin, Q., D. Zhang and J. Lin: Effects of light intensity, stocking density, feeding frequency and salinity on the growth of sub-adult seahorses Hippocampus erectus Perry, 1810. Aquaculture, 292, 111-116 (2009).

Lourie, S.A., A.C.J. Vincent and H.J. Hall: Seahorses: An identification guide to the world's species and their conservation. Washington: University of British Columbia and World Wildlife Fund (1999).

Martinez-Cardenas, L. and G. Purser: Effect of stocking density and photoperiod on growth and survival in cultured early juvenile potbellied seahorses Hippocampus abdominalis Lesson, 1827. Aquac. Res., 43, 1536-1549 (2012).

Olivotto, I., M. Planas, N. Simöes, G.J. Holt, M.A. Avella and R. Calado: Advances in breeding and rearing marine ornamentals. J. World Aquac. Soc., 42, 135-166 (2011).

Partridge, G., D. Benetti, J. Stieglitz, J. Hutapea, A. Mcintyre, B. Chen and V. Scholey: The effect of a 24-hour photoperiod on the survival, growth and swim bladder inflation of pre-flexion yellowfin tuna (Thunnus albacares) larvae. Aquaculture, 318, 471-474 (2011).

Payne, M. and R. Rippingale: Rearing west Australian seahorse, Hippocampus subelongatus, juveniles on copepod nauplii and enriched Artemia. Aquaculture, 188, 353-361 (2000).

Scales, $\mathrm{H}$.: Advances in the ecology, biogeography and conservation of seahorses (genus Hippocampus). Progress in Physical Geography, 34, 443-458 (2010).

Sheng, J., Q. Lin, Q. Chen, Y. Gao, L. Shen and J. Lu: Effects of food, temperature and light intensity on the feeding behaviour of threespot juvenile seahorses, Hippocampus trimaculatus Leach. Aquaculture, 256, 596-607 (2006).

Short, F.T., B. Polidoro, S.R. Livingstone, K.E. Carpenter, S. Bandeira, J.S. Bujang, H.P. Calumpong, T.J.B. Carruthers, R.G. Coles, W.C. Dennison, P.L.A. Erftemeijer, M.D. Fortes, A.S. Freeman, T.G. Jagtap, A.H.M. Kamal, G.A. Kendrick, W.J. Kenworthy, Y.A. La Nafie, I.M. Nasution, R.J. Orth, A. Prathep, J.C. Sanciangco, B. can Tussenbroek, S.G. Vergara, M. Waycott and J.C. Zieman: Extinction risk assessment of the world's seagrass species. Biological Conservation, 144, 1961-1971 (2011).

Strawn, K.: Life history of the pigmy seahorse, Hippocampus zosterae
Jordan and Gilbert, at Cedar Key, Florida. Copeia, 1958, 16 (1958).

Stuart, K.R. and M. Drawbridge: The effect of photoperiod on larval culture performance of two marine finfish species. Aquaculture, 360-361, 54-57 (2012).

Thuong, T. D. and T. Hoang: Rearing the spotted seahorse Hippocampus kuda by feeding live and frozen copepods collected from shrimp ponds. Aquac. Res., 46, 1356-1362 (2013).

Trippel, E. A., and S.R. Neil: Effects of photoperiod and light intensity on growth and activity of juvenile haddock (Melanogrammus aeglefinus). Aquaculture, 217, 633-645 (2003).

Tucker, J.W.: Marine fish culture. Kluwer Academic Publishers, Norwell, MA, USA, p. 750 (1998).

Vallés, R. and A. Estévez: Light conditions for larval rearing of meagre (Argyrosomusregius). Aquaculture, 376-379, 15-19 (2013).

Villamizar, N., A. García-Alcazar and F. Sánchez-Vázquez: Effect of light spectrum and photoperiod on the growth, development and survival of European sea bass (Dicentrarchus labrax) larvae. Aquaculture, 292, 80-86 (2009).

Vincent, A.C.J., S.J. Foster and H.J. Koldewey: Conservation and management of seahorses and other Syngnathidae. J. Fish Biol., 78, 1681-1724 (2011).

Wilson, M.J. and A.C.J. Vincent: Preliminary success in closing the life cycle of exploited seahorse species, Hippocampus spp., in captivity. Aquarium Sciences and Conservation, 2, 179- 196 (1998).

Wilson, Z., C. Carter and G. Purser: Nitrogen budgets for juvenile bigbellied seahorse Hippocampus abdominalis fed Artemia, mysids or pelleted feeds. Aquaculture, 255, 233-241 (2006).

Wong, J. and J. Benzie: The effects of temperature, Artemia enrichment, stocking density and light on the growth of juvenile seahorses, Hippocampus whitei (Bleeker, 1855), from Australia. Aquaculture, 228, 107-121 (2003)

Woods, C.: Improving initial survival in cultured seahorses, Hippocampus abdominalis Leeson, 1827 (Teleostei: Syngnathidae). Aquaculture, 190, 377-388 (2000a).

Woods, C.M.: Preliminary observations on breeding and rearing the seahorse Hippocampus abdominalis (Teleostei: Syngnathidae) in captivity. New Zealand J. Mar. Freshwater Res., 34, 475-485 (2000b).

Woods, C.: Effect of stocking density and gender segregation in the seahorse Hippocampus abdominalis. Aquaculture, 218, 167-176 (2003).

Woods, C.M.: Growth of cultured seahorses (Hippocampus abdominalis) in relation to feed ration. Aquac. Inter., 13, 305-314 (2005). 